\title{
Early changes in left ventricular subendocardial function after successful coronary angioplasty
}

\author{
Michael Y Henein, Kim Priestley, Tengis Davarashvili, Nigel Buller, Derek G Gibson
}

\begin{abstract}
Objective-To study the early effects of coronary angioplasty on resting left ventricular long axis function, reflecting that of the subendocardium.

Design-Prospective echocardiographic and Doppler examination of patients with coronary artery disease, before and after single vessel coronary angioplasty. Setting-A tertiary referral centre for cardiac diseases with facilities for invasive and non-invasive investigation.

Patients-23 patients with significant left coronary disease being considered for coronary angioplasty.

Results-Before angioplasty the mean
\end{abstract} (SD) isovolumic relaxation time was longer than normal (75(19) ms $v 55$ (10), $p<0.001)$ with a significant increase in transverse dimension change before mitral valve opening, and peak rate of early diastolic thinning (8(3) $v 10.4(2 \cdot 6)$ $\mathrm{cm} / \mathrm{s}(\mathbf{p}<0.001))$ was reduced. Long axis motion was frequently abnormal. The interval from the onset of the $Q$ wave to the onset of shortening was prolonged (118 (30) ms $v 90$ (19) at the left site and 115 (26) ms $v 81$ (9) at the septal site, $p<0.001$ ) and the onset of early diastolic rapid lengthening delayed with respect to the aortic valve closure sound $\left(A_{2}\right)$ by 85 (34) $\mathrm{ms} v 58$ (11) at the left site and $88(33) \mathrm{ms} v 60$ (9) at the septal site $(p<0.001)$. Although overall amplitude was reduced at the septal site only $(1.23(0.3) \mathrm{cm} v 1.5(0.4), \mathrm{p}<0.05)$, the extent $(0.8(0.2) \mathrm{cm} v 1.04(0.3)$ at the left site and $0.66(0.2) \mathrm{cm} v 0.9(0.3)$ at the septal site, $p<0.001$ ) and peak rate $(6.2(2) \mathrm{cm} / \mathrm{s} v 10(2.5)$ at the left site and $5.4(2 \cdot 3) \mathrm{cm} / \mathrm{s} v 8.5(2)$ at the septal site, p $<001$ ) of early diastolic lengthening were both much lower than normal. The E/A ratio on transmitral Doppler was modestly reduced $(1.0(0 \cdot 7) v 1.4(0.4), p$ < 0.05). After angioplasty: isovolumic relaxation time shortened to $64(18) \mathrm{ms}$ $(p<0.001)$ and left ventricular incoordination regressed. Long axis shortening with respect to $Q(98$ (32) $\mathrm{ms} v 118$ (30) at the left site and 94 (23) ms $v 115$ (26) at the septal site, $p<0 \cdot 01$ ) and that of lengthening with respect to $A_{2}$ both normalised. Early diastolic peak lengthening rate increased $(7 \cdot 5(2 \cdot 1) \mathrm{cm} / \mathrm{s} v 6 \cdot 2$ (2) at the left site, and $6.3(2.4) \mathrm{cm} / \mathrm{s} v$ $5.4(2 \cdot 3)$ at the septal site, p $<0.001)$. The early diastolic peak thinning rate of the posterior wall significantly increased $(10(3.5) \mathrm{cm} / \mathrm{s}$ v $8(3), \mathrm{p}<0.005)$ as did mitral E/A ratio $1.2(0 \cdot 7) v 1.0(0 \cdot 7), \mathrm{p}<$ 0.05).

Conclusion-Long axis motion, representing the function of longitudinally arranged subendocardial fibres, is consistently abnormal in the resting state in coronary artery disease. These systolic and diastolic abnormalities return towards normal after successful angioplasty, suggesting that they are the direct effect of coronary artery stenosis.

(Br Heart f 1993;69:501-506)

Changes in the left ventricular minor axis, as recorded by $M$ mode echocardiography, have proved useful in documenting abnormal diastolic function in left ventricular hypertrophy, ${ }^{1}$ diabetes, ${ }^{23}$ and coronary artery disease. ${ }^{4}$ Though the method has been recently supplanted to a considerable extent by Doppler echocardiography, ${ }^{5}$ reservations are now being expressed as to the validity of Doppler echocardiography in studying diastolic function. ${ }^{6}$ In left ventricular hypertrophy and coronary artery disease the two techniques do not give identical information ${ }^{78}$; Doppler estimates of filling pattern are very sensitive to events during isovolumic relaxation contrasting strikingly with changes in left ventricular minor axis. In our study, therefore, we aimed to extend earlier work by noting changes in left ventricular long as well as minor axis in patients with ischaemic heart disease. We chose a group of patients with significant coronary artery disease ( $>70 \%$ stenosis), studying them before and soon after successful percutaneous single vessel coronary angioplasty. Although subject to angina of effort before the procedure, patients were studied at rest, and all were symptom free at the time when measurements were obtained.

\section{Patients and methods}

PATIENTS

Twenty three patients with significant coronary artery disease and exercise induced stable angina were studied. All patients subsequently underwent successful single vessel coronary angioplasty defined as a residual stenosis of $<50 \%$ and no appreciable procedural complications. Twelve patients, mean age 63 (SD 9) years (group I, $11 \mathrm{men}$ ), had single vessel disease and no history of myocardial infarction or cardiac surgery. Ten had disease of the left anterior descending artery: eight proximal and two midvessel; one had disease in the distal circumflex and one 
in the obtuse marginal branch of the circumflex artery. Of the remaining 11 patients (group II) 10 had multivessel disease (two had a previous anterior $Q$ wave myocardial infarction), and five patients had undergone coronary bypass surgery; all were men of mean (SD) age 55 (13) years. In all 11 patients one culprit vessel was successfully dilated. This was the left anterior descending artery itself in six patients (proximal in three, midvessel in two, and distal in one), the ostium of a left anterior descending vein graft in one patient, and the circumflex in four patients (one proximal and three distal).

\section{TREATMENT}

All the patients were subject to exercise limiting angina incompletely controlled by medical treatment with individualised combinations of nitrates and calcium channel and $\beta$ blocking drugs. Apart from minor and inconsistent alteration, medication was the same after angioplasty. The results from these patients were compared with those in 21 normal subjects, mean age 51 (11) years, none of whom had any evidence of cardiovascular disease or hypertension. All patients and normal subjects were in sinus rhythm.

\section{METHODS}

Patients and controls were studied under resting conditions and had undertaken no unusual physical exertion before the test. We obtained $M$ mode and cross sectional echocardiograms with a Hewlett-Packard model 77020 A Sonos 1000 echocardiograph with a $2.5 \mathrm{MHz}$ transducer before and within 48 hours of angioplasty, with the patient lying in the left lateral position. The $\mathbf{M}$ mode echocardiograms and Doppler mitral velocity traces were recorded separately on a Honeywell (Ecoline 22) strip chart recorder at a paper speed of $100 \mathrm{~mm}$ with simultaneous electrocardiogram and phonocardiogram.

Standard $M$ mode echocardiograms of the left ventricular minor axis were recorded at the tips of mitral valve leaflets. We also obtained $M$ mode echocardiograms of the left ventricular long axis represented by atrioventricular ring motion that reflects longitudinal ventricular function, with the cursor longitudinally placed through the left, central fibrous body (septal) and right sites of the atrioventricular ring seen on the apical four chamber view $^{9}$ (fig 1).

Mitral early and late diastolic flow velocities were measured from the cardiac apex by pulsed Doppler with either the HewlettPackard or a Doptek system with a $2 \mathrm{MHz}$ transducer, and were recorded with frequency shift calibration. Echocardiograms were matched for heart rate; the onset of the $Q$ wave was used to time early systolic events and the first high frequency component of the aortic valve closure sound $\left(\mathrm{A}_{2}\right)$ for early diastolic events. The echocardiograms were digitised $^{10}$ to find peak rates of change of dimension and wall thickness.

We took isovolumic relaxation time as the time interval between aortic valve closure and

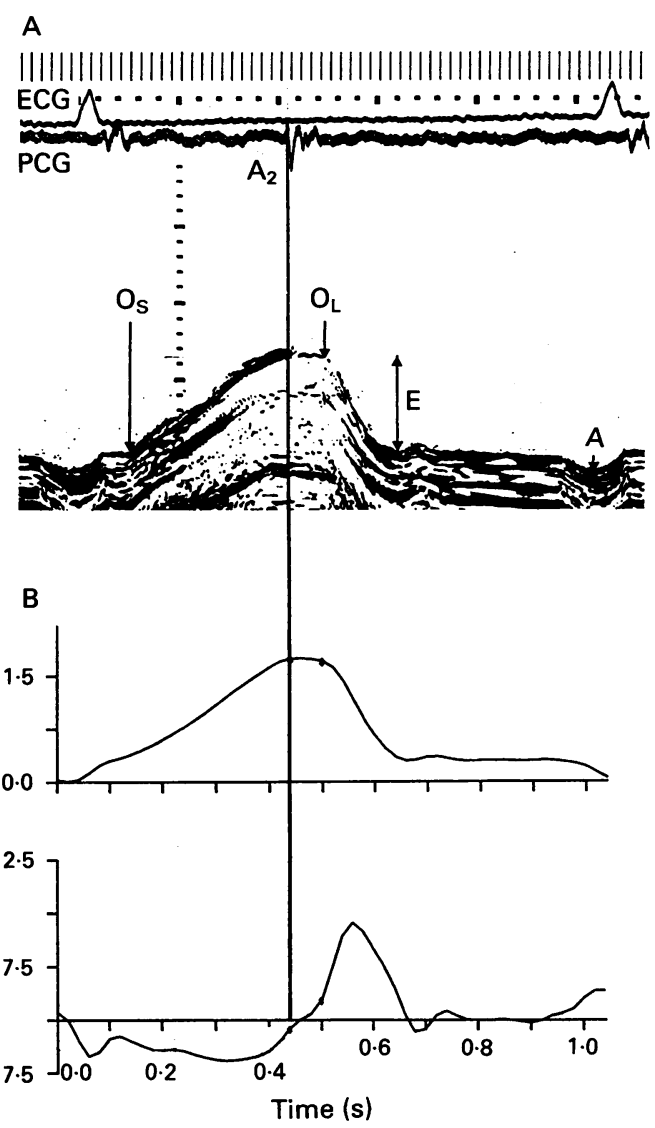

Figure 1 (A) Long axis $M$ mode recording from a healthy control recorded at left site. Vertical scale in $\mathrm{cm}$. (B) The upper panel shows the digitised plot of the trace, the lower panel shows its rate of change. Vertical line corresponds to $A_{2}$. ECG, electrocardiogram; $P C G$, phonocardiogram; $A_{2}$, aortic closure; $O_{v}$ onset of long axis shortening; $O_{L}$ onset of long axis lengthening; $E$, early diastolic excursion; $A$, atrial systolic excursion.

the onset of mitral valve cusp separation (ms). End systolic dimension was taken as the transverse diameter between the left ventricular septum and posterior wall at $A_{2}(\mathrm{~cm})$, end:? diastolic dimension as the transverse diameter at the time of the onset of the $Q$ wave of the electrocardiogram $(\mathrm{cm})$. The peak rate of posterior wall thinning was measured as theo early diastolic velocity of the posterior wall $(\mathrm{cm} / \mathrm{s})$.

For the left sided, septal, and right sided long axis traces, we measured the intervals ${ }^{\circ}$ between $Q$ and the onset of shortening and $Q \mathcal{S}$ and the minimum left ventricular dimensionew (ms) and thus found the duration of shortening as the difference between the two. Also we measured the overall amplitude of atrioventricular ring motion $(\mathrm{cm})$, early diastolic excursion $(\mathrm{cm})$; from peak inward motion to the position at the onset of diastasis, that dur- $-\vec{\Phi}$ ing atrial systole was measured as the $A$ wave $\frac{\vec{D}}{\mathrm{D}}$ occurring after the $P$ wave in the electrocardiogram. Peak rate of early diastolic lengthening was measured from the digitised traceso and onset of rapid outward motion was the shoulder angling point between shortening and lengthening. From the Doppler traces we measured the peak early $E$ and atrial $A$ wave velocities, the $E / A$ ratio, and the time interval from $A_{2}$ to the onset and peak of mitral $E$ wave (ms). 


\section{STATISTICS}

Values represent mean (SD). We used unpaired $t$ tests to compare normal subjects with patients undergoing percutaneous transluminal coronary angioplasty. Patients before and after angioplasty were compared by paired $t$ tests. A $5 \%$ probability was taken as significant. In individual patients, values were considered abnormal when they were more than two SDs from the corresponding normal mean. Results from the two patient subgroups were examined separately and subsequently pooled in view of their overall similarity. Minor but significant differences between the two are presented separately. Differences between the two were subsequently investigated by unpaired $t$ test both in their difference from normal and their response to angioplasty.

Table 1 Isovolumic relaxation time and dimension changes

\begin{tabular}{lccc}
\hline Indices & $\begin{array}{l}\text { Normal } \\
(n=21)\end{array}$ & $\begin{array}{l}\text { Before PTCA } \\
(n=23)\end{array}$ & $\begin{array}{l}\text { After PTCA } \\
(v \text { before PTCA })\end{array}$ \\
\hline RR interval (ms) & $940(240)$ & $950(230)$ & $-15(87)$ \\
IVR time (ms) & $55(10)$ & $75(19)^{\star \star}$ & $-12(9) \dagger$ \\
IVR dimension changes M (cm) & $0 \cdot 13(0.07)$ & $-0 \cdot 23(0 \cdot 2)^{\star}$ & $-0.05(0.3)$ \\
IVR dimension changes L (cm) & $0 \cdot 16(0.16)$ & $-0.04(0 \cdot)^{\star}$ & $-0.03(0.2)$ \\
IVR dimension changes S (cm) & $0 \cdot 1(0 \cdot 06)$ & $+0.03(0.2)^{\star \star}$ & $-0.07(0.2)$ \\
\hline
\end{tabular}

${ }^{\star} \mathrm{p}<0.05 ;{ }^{\star \star} \mathrm{p}<0.01 v$ normal; tp $<0.05 ;$ PTCA, percutaneous transluminary coronary angioplasty; $L$, left; $S$, septal, sites; IVR, isovolumic relaxation; $M$, minor axis; + , inward movement before PTCA; -, outward movement before PTCA; values are mean (SD).

Table 2 mode echocardiographic data.

\begin{tabular}{|c|c|c|c|}
\hline Indices & $\begin{array}{l}\text { Normal } \\
(n=21)\end{array}$ & $\begin{array}{l}\text { Before PTCA } \\
(n=23)\end{array}$ & $\begin{array}{l}\text { After PTCA } \\
\text { (vs before PTCA) }\end{array}$ \\
\hline $\begin{array}{l}\text { Total excursion } M(\mathrm{~cm}) \\
\text { Total excursion } L(\mathrm{~cm}) \\
\text { Early diastolic excursion } L(\mathrm{~cm}) \\
\text { Atrial systole } L(\mathrm{~cm}) \\
\text { Total excursion } S(\mathrm{~cm}) \\
\text { Early diastolic excursion } S(\mathrm{~cm}) \\
\text { Atrial systole } S(\mathrm{~cm}) \\
\text { Peak rate of thinning } M(\mathrm{~cm} / \mathrm{s}) \\
\text { Peak rate of lengthening } L(\mathrm{~cm} / \mathrm{s}) \\
\text { Peak rate of lengthening } S(\mathrm{~cm} / \mathrm{s}) \\
A_{2} \text { to the onset of lengthening } L(\mathrm{~ms}) \\
A_{2} \text { to the onset of lengthening } S(\mathrm{~ms})\end{array}$ & $\begin{array}{l}1 \cdot 7(0 \cdot 3) \\
1.5(0 \cdot 3) \\
1.04(0 \cdot 3) \\
0 \cdot 4(0 \cdot 1) \\
1.5(0 \cdot 4) \\
0 \cdot 9(0 \cdot 3) \\
0.5(0 \cdot 2) \\
10 \cdot 4(2 \cdot 6) \\
10(2 \cdot 5) \\
8 \cdot 5(2) \\
58(11) \\
60(9)\end{array}$ & $\begin{array}{l}1 \cdot 8(0 \cdot 4) \\
1 \cdot 46(0 \cdot 31) \\
0 \cdot 8(0 \cdot 2)^{\star \star} \\
0 \cdot 62(0 \cdot 14)^{\star \star} \\
1 \cdot 23(0 \cdot 3)^{\star} \\
0 \cdot 66(0 \cdot 2)^{\star \star} \\
0 \cdot 57(0 \cdot 11) \\
8(3)^{\star} \\
6 \cdot 2(2)^{\star \star} \\
5 \cdot 4(2 \cdot 3)^{\star \star} \\
85(34)^{\star \star} \\
88(33)^{\star \star}\end{array}$ & $\begin{array}{l}+0.18(0.4) \\
+0.04(0.3) \\
+0.1(0.2) \\
-0.1(0.15) \ddagger \\
+0.05(0.3) \\
+0.06(0.2) \\
-0.01(0.13) \\
+2(2 \cdot 8) \ddagger \\
+1.3(1.5) \ddagger \\
+0.9(1.3) \ddagger \\
-17(25) \ddagger \\
-21(14) \ddagger\end{array}$ \\
\hline
\end{tabular}

${ }^{\star} \mathrm{p}<0.05 ;{ }^{\star \star} \mathrm{p}<0.01 v$ normal; $\neq \mathrm{p}<0.01 v$ before PTCA; PTCA, percutaneous transluminary coronary angioplasty; $M$, minor axis; $L$, left; S, septal, sites; values are mean (SD).

Table 3 Early systolic changes

\begin{tabular}{lcll}
\hline Indices & $\begin{array}{l}\text { Normal } \\
(n=21)\end{array}$ & $\begin{array}{l}\text { Before PTCA } \\
(n=23)\end{array}$ & $\begin{array}{l}\text { After PTCA } \\
\text { (v before PTCA) }\end{array}$ \\
\hline Q to the onset of shortening M (ms) & $81(10)$ & $113(24)^{\star \star}$ & $-17(27) \ddagger$ \\
Q to the onset of shortening L (ms) & $90(19)$ & $118(30)^{\star \star}$ & $-19(27) \neq$ \\
Onset to minimum dimension L (ms) & $272(50)$ & $300(65)$ & $-18(130)$ \\
Q to the onset of shortening S (ms) & $81(9)$ & $115(26)^{\star \star}$ & $-20(27) \ddagger$ \\
Onset to minimum dimension S (ms) & $300(48)$ & $350(75)$ & $-52(97)$ \\
\hline
\end{tabular}

${ }^{\star} \mathrm{p}<0.05 ;{ }^{\star \star} \mathrm{p}<0.01 v$ normal; $\neq \mathrm{p}<0.01 v$ before PTCA; PTCA, percutaneous transluminary coronary angioplasty; $M$, minor axis; $L$, left; $S$, septal sites; values are mean (SD).

Table 4 Doppler findings

\begin{tabular}{lccc}
\hline Indices & $\begin{array}{l}\text { Normal } \\
(n=21)\end{array}$ & $\begin{array}{l}\text { Before PTCA } \\
(n=23)\end{array}$ & $\begin{array}{l}\text { After PTCA } \\
\text { (v before PTCA })\end{array}$ \\
\hline E wave $(\mathrm{m} / \mathrm{s})$ & $0 \cdot 7(0 \cdot 1)$ & $0.4(0 \cdot 2)$ & $+0 \cdot 1(0 \cdot 15) \ddagger$ \\
A wave $(\mathrm{m} / \mathrm{s})$ & $0 \cdot 5(0 \cdot 1)$ & $0.5(0 \cdot 3)$ & $-0 \cdot 02(0 \cdot 17)$ \\
E/A ratio & $1 \cdot 4(0 \cdot 4)$ & $1 \cdot 0(0 \cdot 7)^{\star}$ & $+0 \cdot 26(0.6) \dagger$ \\
$\mathrm{A}_{2}$ to the onset of E (ms) & $84(14)$ & $100(20)$ & $-20(12) \ddagger$ \\
$\mathrm{A}_{2}$ to the peak of $\mathrm{E}(\mathrm{ms})$ & $165(28)$ & $168(28)$ & $-16(19) \dagger$ \\
\hline
\end{tabular}

${ }^{\star} \mathrm{p}<0.05 v$ normal; $\mathrm{tp}<0.05 ; \neq \mathrm{p}<0.01 v$ before PTCA; PTCA, percutaneous transluminary coronary angioplasty; $\mathrm{E}$, early diastolic mitral flow velocity; $A$, late diastolic mitral flow velocity; $\mathrm{A}_{2}$, timing of aortic valve closure; values are mean (SD).

\section{Results}

NORMAL SUBJECTS:

Tables 1-4 show that left ventricular cavity size and wall motion were both by definition normal in these subjects. Isovolumic relaxation time had a mean value of $55 \mathrm{~ms}$, and no significant dimension change occurred during this period. Long axis shortening began 80-90 ms after the onset of the $Q$ wave of the electrocardiogram, and lengthening started $60 \mathrm{~ms}$ after $\mathrm{A}_{2}$ - that is, at about the same time as mitral cusp separation and $20 \mathrm{~ms}$ before the first detectable transmitral flow on pulsed Doppler. The greater part of backward displacement of the mitral ring occurred during early diastole with a peak velocity of $8 \cdot 5-10 \mathrm{~cm} / \mathrm{s}$ (fig 2 ).

\section{COMPARISON WITH PATIENTS WITH CORONARY} ARTERY DISEASE:

Table 1-4 show that the mean values of $R R$ interval, cavity size, and shortening fraction did not differ from normal. Isovolumic relaxation time was, however, significantly prolonged, with further shortening of the septal long axis consistently occurring during this

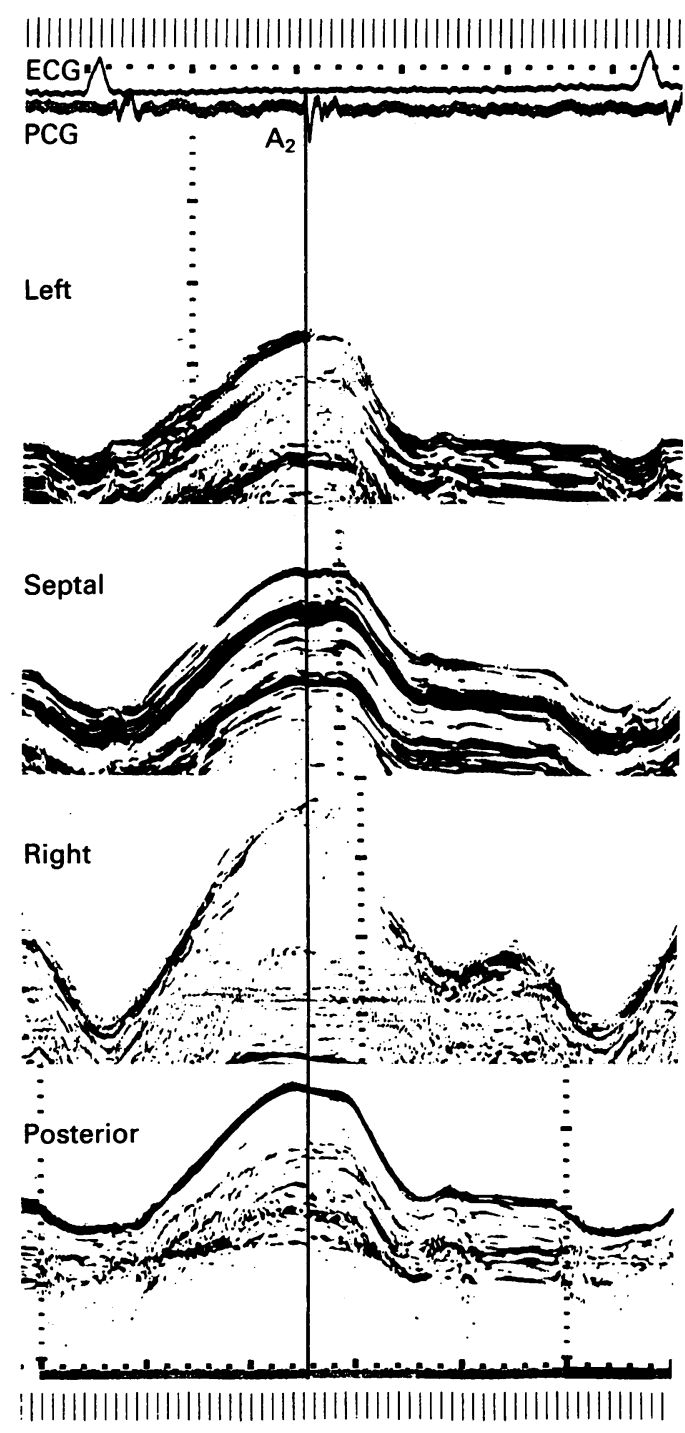

Figure 2 Long axis $M$ mode recordings from a normal subject taken at left, septal, right, and posterior sites. Traces are recorded with simultaneous ECG and PCG Vertical line corresponds to $A_{2}$. Abbreviations as fig. 1 . 
A

||||||||||||||||||||||||||||||||||||||||||||||||||||||||||||||||||

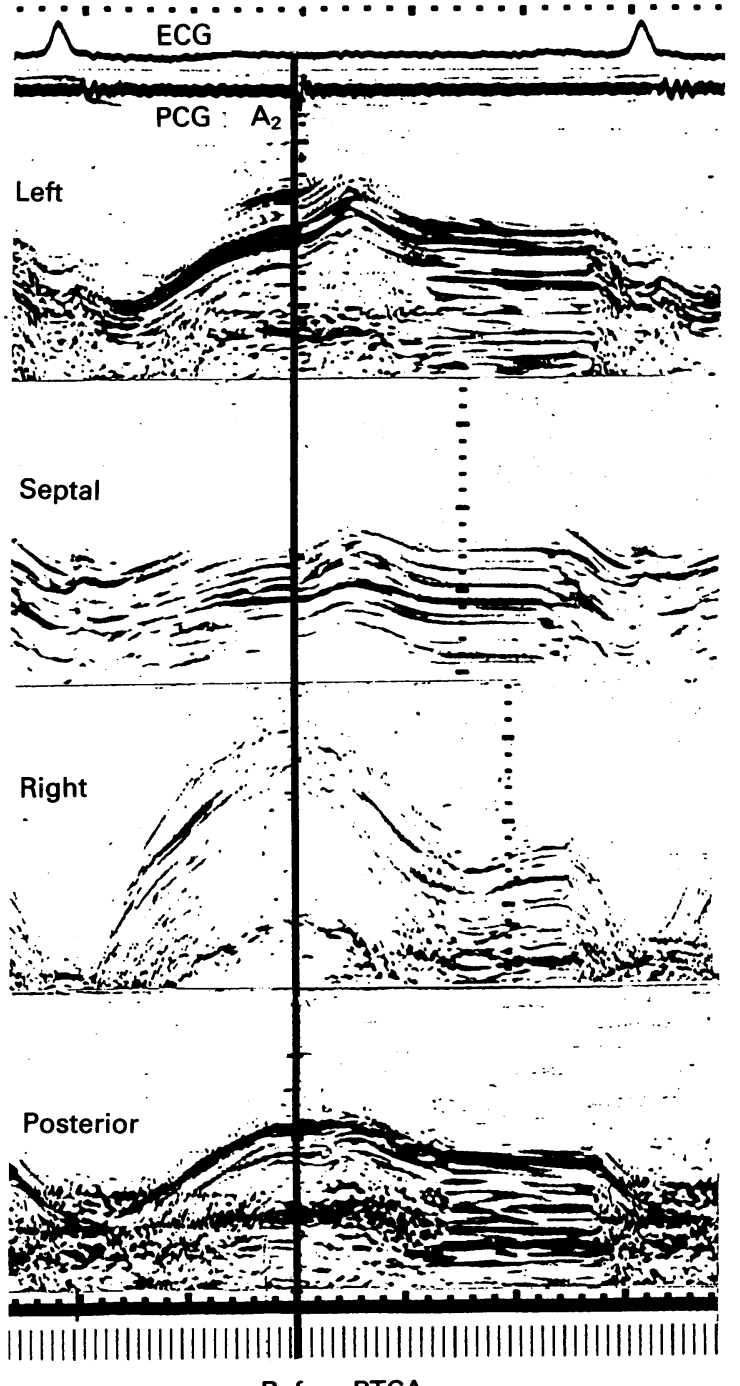

B

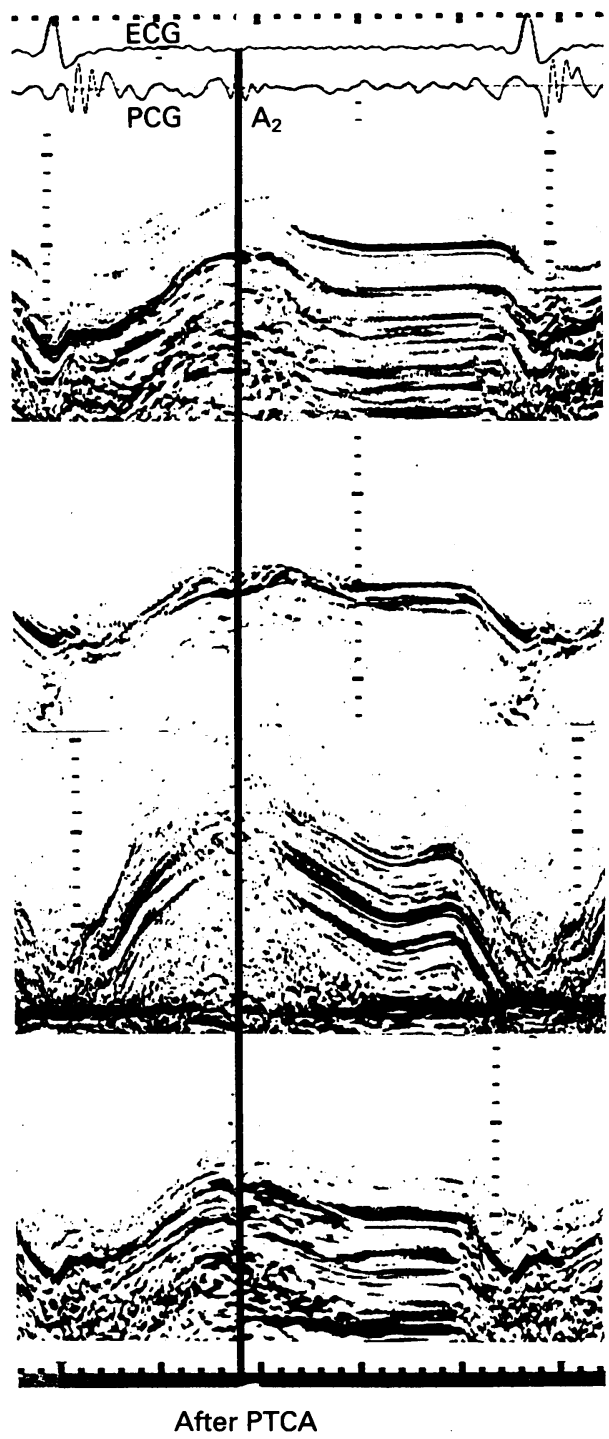

After PTCA

Figure 3 (A) Long axis $M$ mode recording from a patient with severe left anterior descending artery stenosis. Note the delay in the onset of shortening with respect to the $Q$ wave on the electrocardiogram, the prolonged inward motion after $A$ and the decreased early diastolic excursion and lengthening rate. (B) Long axis from the same patient after successful angioplasty. Note how these disturbances have returned towards normal. Abbreviations as for fig. 1.

period (fig 3A). The onset of shortening at the start of systole was characteristically delayed at the septal and left sites, the interval from $Q$ to the onset of shortening being delayed by about $30 \mathrm{~ms}$ at both. The onset of rapid lengthening with respect to $A_{2}$ was also delayed, and again by a very similar amount. During the prolonged period of isovolumic relaxation, incoordinate wall motion was present affecting the septum, which showed further shortening before mitral cusp separation.

Disturbances of filling were also common. The extent and peak rate of early diastolic lengthening were both reduced at septal and left sites with a reciprocal increase in the amplitude of ring motion during atrial systole. Peak E and A wave velocities showed no consistent change although the $\mathrm{E} / \mathrm{A}$ ratio was reduced.

EFFECTS OF ANGIOPLASTY

Angioplasty did not effect RR interval, but isovolumic relaxation consistently fell by
$20 \mathrm{~ms}$. On the transmitral Doppler, E wave velocity increased, along with $\mathrm{E} / \mathrm{A}$ ratio, but A wave velocities were unaffected.

Abnormalities of long axis function present $\stackrel{\sigma}{N}$ under control conditions were also consis- $N$ tently affected, tending to return towards nor- N mal (fig 3(B)). The time intervals from the $Q$ wave of the electrocardiogram to the onset of inward motion and from $A_{2}$ to the onset of rapid lengthening both fell by $20 \mathrm{~ms}$ - that is, by about two thirds of the initial abnormality. Disturbances of early diastole also regressed: the extent and peak rate of early diastolic lengthening both increased and $A$ wave $\AA$ decreased as the Doppler filling pattern returned towards normal. There was no sig- 8 nificant correlation between peak $\mathrm{E}$ wave velocity and peak rate of early diastolic lengthening.

COMPARISON BETWEEN THE TWO SUBGROUPS Table 5 shows that when patients with single vessel coronary artery disease (group I) were 
Table 5 Differences between two patient subgroups

\begin{tabular}{lccc}
\hline Variable & $\begin{array}{l}\text { Single vessel } \\
\text { disease }(n=12)\end{array}$ & $\begin{array}{l}\text { Multivessel } \\
\text { disease }(n=11)\end{array}$ & $\begin{array}{l}p \\
\text { Value }\end{array}$ \\
\hline Before angioplasty: & & & \\
Fractional shortening & $0.35(0.04)$ & $0.32(0.05)$ & $<0.05$ \\
Q to the onset shortening S (ms) & $103(21)$ & $129(27)$ & $<0.02$ \\
Q to the minimum dimension S (ms) & $433(62)$ & $508(63)$ & $<0.02$ \\
After angioplasty: & $-0.23(0.12)$ & $0.01(0.13)$ & $<0.05$ \\
IVR dimension change L (cm) & $59(22)$ & $76(22)$ & $<0.05$ \\
A to the onset lengthening L (ms) & $1.0(0.2)$ & $0.76(0.2)$ & $<0.05$ \\
Early diastolic excursion L (cm) & & & \\
\hline
\end{tabular}

IVR, isovolumic relaxation; $L$, left long axis site; $S$, septal long axis site; values are mean (SD).

compared with those with multivessel disease and or coronary bypass grafting (group II) their overall behaviour was similar. We did find, however, that in the control state fractional shortening was greater and that the delay in onset of long axis shortening in early systole and of lengthening in early diastole were both significantly less in group I patients. After angioplasty, normalisation of dimension changes during isovolumic relaxation and early diastole were all more complete in group I patients. Differences between the two groups for all the other measurements made were not significant.

\section{RESULTS IN INDIVIDUAL PATIENTS}

Table 6 gives the numbers of patients in whom individual values fell outside the $95 \%$ confidence intervals ( $95 \% \mathrm{CIs)}$ of normal. The disturbances most commonly abnormal were $Q$ to the onset of shortening, $A_{2}$ to the onset of rapid lengthening and peak rate of early diastolic lengthening, followed by peak $E$ wave velocity, and isovolumic relaxation time. Either $Q$ to the onset of shortening, $A_{2}$ to the onset of rapid lengthening, or peak rate of lengthening in early diastole were abnormal in all but one patient before angioplasty. The variables that became normal most frequently were $Q$ to the onset of shortening, peak rate of early diastolic lengthening, and isovolumic relaxation time, each of them over $50 \%$. The $\mathrm{E}$ wave velocity and $\mathrm{A}_{2}$ to the onset of rapid outward motion were significantly less frequently affected. Although change in the $\mathrm{E} / \mathrm{A}$ ratio with angioplasty was highly significant, values remained within normal limits before and after angioplasty. Peak rate of early diastolic lengthening increased before and after angioplasty.

In individual patients further interrelations between these variables could be defined, when results before and after angioplasty were combined. The delay from $Q$ to the onset of shortening and $A_{2}$ to the onset of rapid lengthening was similar both between

Table 6 Distribution of individual abnormalities (number of patients with values outside $95 \%$ CIs of normal)

\begin{tabular}{lll}
\hline Variables & $\begin{array}{l}\text { Before } \\
\text { PTCA }\end{array}$ & $\begin{array}{l}\text { After } \\
\text { PTCA }\end{array}$ \\
\hline Q to the onset of shortening & 13 & 6 \\
Peak rate of lengthening & 13 & 6 \\
A $_{2}$ to the onset of lengthening & 13 & 8 \\
Peak E wave velocity & 10 & 9 \\
Isovolumic relaxation & 9 & 6 \\
E/A ratio & 2 & 2
\end{tabular}

PTCA, percutaneous transluminary coronary angioplasty; $\mathrm{E}$ early diastolic mitral flow velocity; $A$, late diastolic mitral flow velocity. control and coronary artery disease (about 30 $\mathrm{ms}$ ) and between before and after angioplasty (about $20 \mathrm{~ms}$ ). In patients in whom $Q$ to the onset of inward motion had increased beyond the $95 \% \mathrm{CI}$ of normal, the value of $A_{2}$ to the onset of lengthening was $106(23) \mathrm{ms}$, whereas in those with normal $Q$ to the onset of shortening, lengthening started 85 (19) ms after $A_{2}(p<0.01)$. The relation between $Q$ to the onset of shortening and peak $E$ wave was also striking. When the onset of shortening of both long axes was abnormally delayed $(n=8)$, peak $E$ wave velocity was always reduced to a mean value of $0.25(0 \cdot 13) \mathrm{ms}$. When one long axis only was abnormal ( $\mathrm{n}=$ $16), E$ wave velocity was below the $95 \% \mathrm{CI}$ in eight $(44 \%)$, mean value of $0.47(0.19) \mathrm{ms}$ $(\mathrm{p}<0.05)$. When the movement started normally in both long axes $(n=22), E$ wave velocity was reduced in seven $(30 \%)$ with a mean value of $0.56(0.19) \mathrm{ms}$. Difference from one abnormal axis $(p<0.03)$, and from both axes $(p<0.002)$.

\section{Discussion}

Left ventricular diastolic function is often abnormal in patients with coronary artery disease, even in the absence of acute ischaemia. The rate of decline of left ventricular pressure may be reduced and isovolumic relaxation time prolonged. The filling pattern of the left ventricle may be disturbed, so that the proportion of the stroke volume entering the ventricle during early diastole falls and that entering during atrial systole increases. Regional wall motion may be incoordinate: with segments of myocardium supplied by stenosed coronary arteries showing prolonged inward movement and premature outward motion elsewhere causing a change in cavity shape. ${ }^{11}$ The myocardial fibres most at risk from ischaemia are those situated in the subendocardial region of the myocardium. ${ }^{12}$ These are largely longitudinally directed. ${ }^{13}$ In our study, therefore, we used echocardiography to investigate the incidence and nature of disturbances of left ventricular long axis function in patients undergoing single vessel coronary artery angioplasty. To ascertain the extent to which the disturbances we found were reversible, we studied the patients before and after successful angioplasty.

Long axis function was often abnormal during early diastole in our patients. The most characteristic disturbances were delay in the onset of rapid outward motion and a reduction in peak rate of lengthening of the long axis during early diastole. One or other of these abnormalities was present in all but one of our patients. Less commonly, isovolumic relaxation time was prolonged, and the peak velocity of the $E$ wave was reduced.

The extent of these changes was considerable: isovolumic relaxation time was prolonged and the onset of early diastolic rapid lengthening was delayed, each by about 20 $\mathrm{ms}$, and peak $\mathrm{E}$ wave and peak rate of early diastolic lengthening were both reduced to about $60 \%$ of control values. These changes 
had partially resolved within 48 hours of successful angioplasty strongly suggesting that they were related to the presence of coronary artery stenosis. We conclude, therefore, that left ventricular subendocardial function may be abnormal in patients with coronary artery disease under resting conditions. These disturbances are partially reversed after revascularisation, and so correspond closely to the definition of ischaemia as impaired function caused by interference with tissue or organ perfusion. ${ }^{14}$ Such early diastolic abnormalities thus extend current ideas of silent ischaemia, as they occurred at rest and in the absence of chest pain or electrocardiographic abnormality.

Our results also give some information about the basic mechanisms involved. It is most unlikely that all the changes in function we found were independent of one another. Prolongation of isovolumic relaxation time for example, by whatever mechanism, characteristically reduces peak $\mathrm{E}$ wave velocity. ${ }^{15}$ Any change in the pattern of transmitral flow velocity is thus likely to give only indirect evidence of underlying events. Delay in the onset of rapid lengthening of the long axis at the start of diastole was one of the commonest disturbances. Generally, such delay is likely to have occurred either because the time course of systolic shortening was prolonged, or because the onset of systolic shortening was delayed, or from a combination of these two mechanisms. We therefore studied the early systolic relation between the onset of long axis shortening and the $Q$ wave of the electrocardiogram, and found this interval also to be consistently prolonged by about 30 ms. Not only was this value very similar to the delay in the onset of rapid lengthening, but also it reverted to normal after angioplasty. Delay in the start of long axis shortening occurred early in the cardiac cycle and thus seems to be a primary abnormality. The eventual manifestations are in part diastolic, but the basis is much earlier. It is presumably caused either by a local disturbance of activation or of electromechanical coupling. Normal values for the extent and duration of shortening of these segments make impaired systolic function much less likely. The close relation in individual patients between a delay in the onset of systolic shortening and peak $E$ wave velocity raises the possibility that the low peak rate of early diastolic lengthening may be the direct consequence of a low filling rate. Although we cannot definitely exclude this mechanism, we noted that the timing of the $\mathrm{E}$ wave usually followed that of peak rate of long axis lengthening, and that the direct correlation between the two in individual patients was low. We thus regard delay in the onset of long axis shortening in early systole and a reduction in its peak rate of lengthening in early diastole as two primary disturbances. Changes in cavity shape during isovolumic relaxation and in transmitral flow pattern were secondary to these.

As left ventricular long axis function can so conveniently be studied in humans by combined echo and phonocardiography, and we would stress the necessity of the latter, our results may be useful in assessing patients with coronary artery disease. Values outside the $95 \%$ CIs of normal were often present, allowing individual patients to be recognised. In this long axis function differs strikingly from Doppler measurements, which have previously been reported as changing after angioplasty, but which in our patients remained within normal limits throughout. Disturbed long axis function thus seems a very sensitive indicator of ischaemia that can be identified in individual patients. This allows the effects of angioplasty to be seen, and may thus be useful in assessing the effects of medical or surgical treatment. Clear abnormalities are present at rest, and do not require stress to produce them or specialised imaging to record and interpret the results. Finally, the possibility of detecting abnormalities so intimately related to the presence of ischaemia may well be of potential value in elucidating mechanisms by which myocardial perfusion becomes limited when diastolic time is short. This may lead to a fuller understanding of the basic pathophysiology of ischaemia due to coronary artery disease or related conditions.

Presented at the 65th scientific session of the American Heart Association.

Gibson DG, Traill TA, Hall RJC, Brown DJ. Echocardiographic features of secondary left ventricular hypertrophy. Br Heart f 1979;41:54-9.

2 Shapiro LM, Leatherdale BA, Mackinnon J, Fletcher RF. Left ventricular function in diabetes mellitus 11: relation between clinical features and left ventricular function. Br Heart f 1981;45:129-32.

3 Danielsen $R$, Nordrehaug JE, Lien E, Vik-Mo $H$. Subclinical left ventricular abnormalities in young subjects with long-term type diabetes mellitus detected by digitized M-mode echocardiography. $A m$ I Cardiol 1987;60:143-6.

4 Upton MT, Gibson DG, Brown DJ. Echocardiographic assessment of abnormal left ventricular relaxation in assessment of abnormal left ve

5 Nishimura RA, Abel MD, Hatle LK, Tajik AJ. Assessment of diastolic function of the heart: background and current applications of Doppler echocardiography. Part 11 clinical studies. Mayo Clin Proc 1989;64:181-204.

6 Choong CY, Herrmann HC, Weyman AE, Fifer MA Preload dependence of Doppler-derived indexes of left ventricular diastolic function in humans. $7 \mathrm{Am} C o l$ Cardiol 1987;10:800-8.

7 Lee CH, Hogan JC, Gibson DG. Diastolic disease in left ventricular hypertrophy: comparison of $\mathbf{M}$ mode and Doppler echocardiography for the assessment of rapid ventricular filling. Br Heart f 1991;65:194-200.

8 Spirito P, Maron BJ, Bellotti P, Chiarella F, Vecchio C. Noninvasive assessment of left ventricular diastolic function: comparative analysis of pulsed Doppler ultrasound and digitized M-mode echocardiography. $A m$ m Cardiol 1986;58:837-43.

9 Jones CJH, Raposo L, Gibson DG. Functional importance of the long axis dynamics of the human left venticle. Br Heart F 1990;63:215-20.

10 Gibson DG, Brown D. Measurement of instantaneous left ventricular dimension and filling rate in man, using echocardiography. Br Heart $f$ 1973;35:1 141-9.

11 Gibson DG, Prewitt TA, Brown DJ. Analysis of the left ventricular wall movement during isovolumic relaxation and its relation to coronary artery disease. Br Heart $\mathcal{f}$ 1976;38:1010-9.

12 Cobbe SM. Coronary blood flow and myocardial schaemia. In: Julian DG, Camm AJ, Fox KM, et al. Diseases of the heart. 1st ed. London: Bailliere Tindall, 1989:1091-2.

13 Williams PL Warwick R Myocardial architecture. In: ed. Edinburgh: Churchill Livingstone, 1980:657-9.

14 Woolf $\mathrm{N}$. Ischaemia and infarction; In: McGee JO'D, Isaacson PG, Wright NA, eds. Oxford textbook of patho

15 Brecker SJD, Lee CH, Gibson DG. Relation of left ventricular isovolumic relaxation time and incoordination to transmitral Doppler filling patterns. Br Heart $f$ 1992:68:567-73. 